\title{
DISSOCIATION OF VASCULAR RESISTANCE WITH ENDOCRINE PANCREAS SECRETION: THE EFFECTS OF EPOXYMETHANO ANALOGS OF $\mathrm{PGH}_{2}$.
}

\author{
J.0. Akpan, M.C. Hurley, S. Pek, W.E.M. Lands. Department of \\ Internal Medicine (Division of Endocrinology and Metabolism \\ and The Metabolism Research Unit) and Department of Biological \\ Chemistry, The University of Michigan, Ann Arbor, Michigan 48109 \\ USA (Reprint requests to JOA, University of Ilorin, Ilorin, \\ Nigeria).
}

\section{$\underline{\text { ABSTRACT }}$}

The epoxymethano analogs of $\mathrm{PGH}_{2}$ caused rapid and persistent increase in perfusion pressure in isolated rat pancreata without significant effect on glucagon and insulin secretory responses to $\mathrm{PGH}_{2}$ and $\mathrm{PGE}_{2}$. The changes in perfusion pressure are interpreted as alterations in vascular resistance since the flow rate was kept constant at $2.5 \mathrm{~mL}$ per min. $\mathrm{PGH}_{2}$ alone caused significant elevation in pressure. However, $\mathrm{PGH} 2$ administration superimposed upon an infused epoxymethano analog of $\mathrm{PGH}_{2}$, decreased perfusion pressure significantly, whereas $\mathrm{PGH}_{2}$ induced hormone release was not decreased. The analogs neither stimulated nor inhibited the endocrine pancreas secretion. Thesa studies provide evidence for complete dissociation of vascular constriction from pancreatic hormone release and further suggest that the effects of $\mathrm{PGH}_{2}$ on islet hormone secretion may result from the conversion of $\mathrm{PGH}_{2}$ to other prostanoids.

\section{INTRODUCTION}

Previous reports $(1,2,3,4)$ demonstrate that the synthetic analogs of endoperoxide, 9,11- and 11,9-(epoxymethano)-azoprosta-5,13dienoic acid are stable analogs of prostaglandin $\mathrm{H}_{2}$ (15-hydroxy9,11-peroxidoprosta-5,13-dienoic acid). The epoxymethano analogs of $\mathrm{PGH}_{2}$ have been shown to inhibit the endoperoxide synthase and thromboxane synthase activity $(3,4)$. The endoperoxide analogs are receptor level antagonists of both platelet aggregation and cyclic AMP lowering actions of $\mathrm{PGH}_{2}(4,5)$.

Injection of 9-epoxy-11-methano into canine superior mesenteric artery caused dose dependent vasoconstriction and decrease in 
blood flow. However, $\mathrm{PGH}_{2}$ injected similarly, resulted in vasodilation and increase in blood flow (6). Many prostaglandins exert potent pressor effects on the endocrine pancreas $(7,8)$. The mechanism by which some prostaglandins inhibit the endocrine pancreas secretion has been attributed in part to local vasoconstriction $(7,8)$. In these studies, we have observed that 11 epoxy-9-methano analog which exerts potent vasoconstriction on pancreatic vasculature, neither stimulates nor inhibits secretion nor antagonizes insulin and glucagon secretion in response to $\mathrm{PGH}_{2}$ and $\mathrm{PGE}_{2}$.

\section{MATERIALS AND METHODS}

Pancreata were obtained from young adult male albino rats, weighing from 250-300 g, that were fasted for 18-24 h. The animals were anesthetized with sodium pentobarbital $(50 \mathrm{mg} / \mathrm{kg}$ ) injected intraperitoneally and the pancreas with its intact vasculature was removed and transferred to an extracorporeal perfusion apparatus, as described previously (9) and perfused with KrebsRinger-bicarbonate buffer containing 30 uM albumin, 56 uM dextran and $5.6 \mathrm{mM}$ D-glucose, with or without epoxymethano analogs of $\mathrm{PGH}_{2}$.

$\mathrm{PGH}_{2}$ was generated enzymatically from arachidonate as described previously (10) and was stored frozen. 11-epoxy-9-methano and 9-epoxy-11-methano analogs of endoperoxide $\mathrm{PGH}_{2}$ and $\mathrm{PGE}_{2}$ were donated by Dr. John Pike of the Upjohn Company, Kalamazoo, MI. On the day of use, the epoxymethano analogs were dissolved in 95\% ethanol and then diluted with perfusion buffer to the desired concentration. $\mathrm{PGH}_{2}$ and $\mathrm{PGE}_{2}$ were dissolved in $95 \%$ ethanol and then diluted with perfusion buffer five seconds before use. The final concentration of ethanol in the perfusate was less than $0.95 \%$. We have shown previously that at this concentration ethanol does not affect secretion of glucagon or insulin $(9,10$, 11).

The perfusion flow rate was maintained constant at $2.5 \mathrm{~mL}$ per min. Perfusion pressure was monitored continuously using a pressure transducer, an amplifier and a strip-chart recorder set either at 0.2 in (or at 2 in per min during injection of $\mathrm{PGH}_{2}$ ). $\mathrm{PGH}_{2}$ and $\mathrm{PGE}_{2}$ were administered as a 250 uL bolus over $5-8$ seconds through a diaphram in the influent line without interrupting the flow of the basic perfusion solution. $\mathrm{PGH}_{2}$ injections were made before, during and after perfusing the pancreata with buffer solution containing 1 uM epoxymethano analogs. The pancreatic portal venous effluent was collected in one-minute fractions; the samples were chilled immediately and aliquoted for radioimmunoassays. Radioimmunoassays for glucagon and insulin were performed using a "double-antibody" method described previously (12). Statistical significance of differences between observed values was determined by two-tailed student t-test. Values are mean \pm SEM. 


\section{RESULTS}

The pancreas was perfused firstly, for 20 minutes with basic buffer solution containing $5.6 \mathrm{mM}$ glucose (described in MATERIALS AND METHODS) without the endoperoxide analogs. The influent perfusate was then switched to a solution containing 1 uM 11-epoxy9-methano analog of $\mathrm{PGH}_{2}$ and perfusion was continued further for 60 minutes. The influent perfusate was lastly switched again to the basic buffer solution. $\mathrm{PGH}_{2}$ or $\mathrm{PGE}_{2}$ was injected as a $250 \mathrm{uL}$ bolus into the pancreas before, during and after perfusing the pancreata with solution containing the endoperoxide analogs.

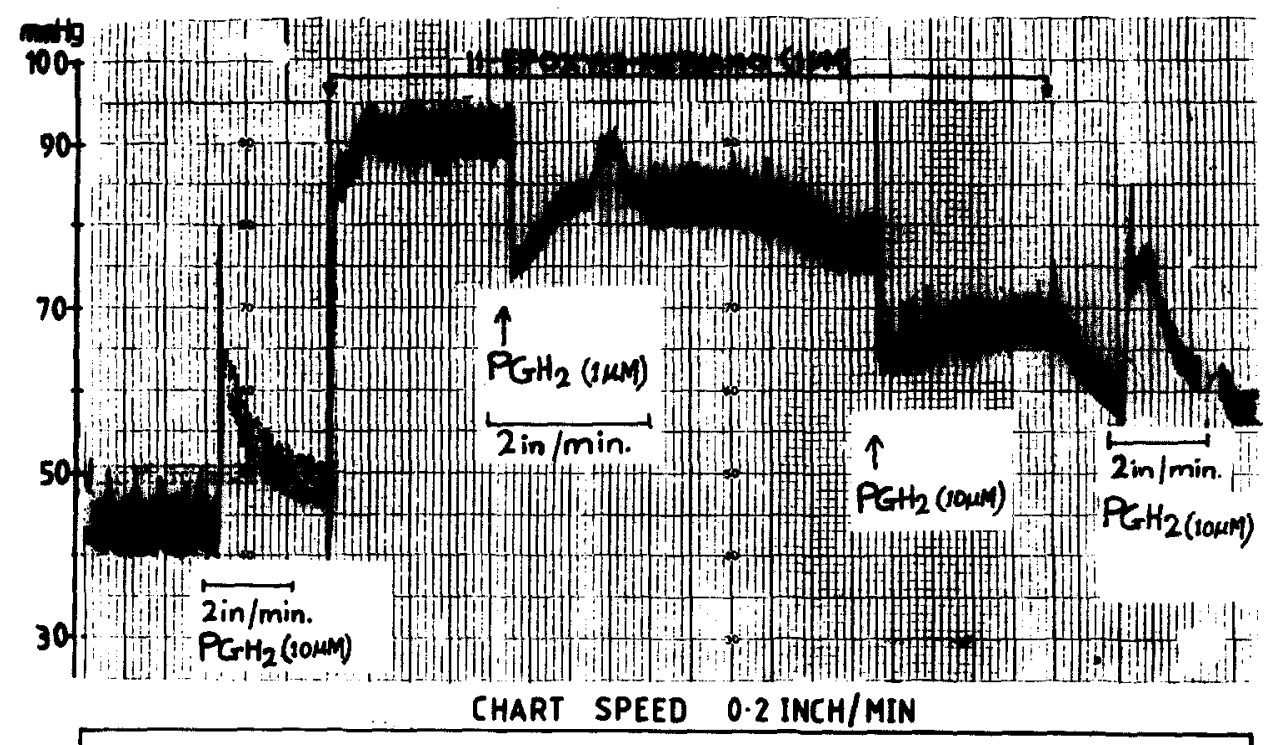

Fig. 1. $\mathrm{PGH}_{2}$ and endoperoxide analog induced changes in perfusion pressure. Flow rate was maintained constant at $2.5 \mathrm{~mL} / \mathrm{min}$. Recording speed was set at $0.2 \mathrm{in} / \mathrm{min}$ (or increased to $2 \mathrm{in} / \mathrm{min}$ during injection of $\mathrm{PGH}_{2}$ only). $\mathrm{PGH}_{2}$ was injected at various intervals before, during and after perfusion with the analog. Pressure values are in milimeter of mercury.

In Figure 1 is shown qualitative perfusion pressure recordings obtained during one of the experiments. 11-epoxy-9-methano alone or 9-epoxy-11-methano (data not shown) caused rapid and persistent increase in the perfusion pressure. PGH $(10 \mathrm{uM})$ alone injected before the endoperoxide analog, also exerted significant, although lesser increase in pressure (Figure 1, left panel). $\mathrm{PGH}_{2}$ ( $1 \mathrm{uM}$ or $10 \mathrm{uM}$ ) injections superimposed upon influent endoperoxide analog, decreased significantly the high perfusion pressure caused by the analog (Figure 1, middle panel). When the influent perfusate was switched off the analog and the pancreas was perfused with basic buffer solution, perfusion pressure gradually returned almost to baseline in five minutes. $\mathrm{PGH}_{2}$ again 
increased the perfusion pressure (Figure 1, right panel). The changes in pressure observed in these studies are interpreted as alterations in vascular resistance since the flow rate was maintained constant at $2.5 \mathrm{~mL}$ per minute.

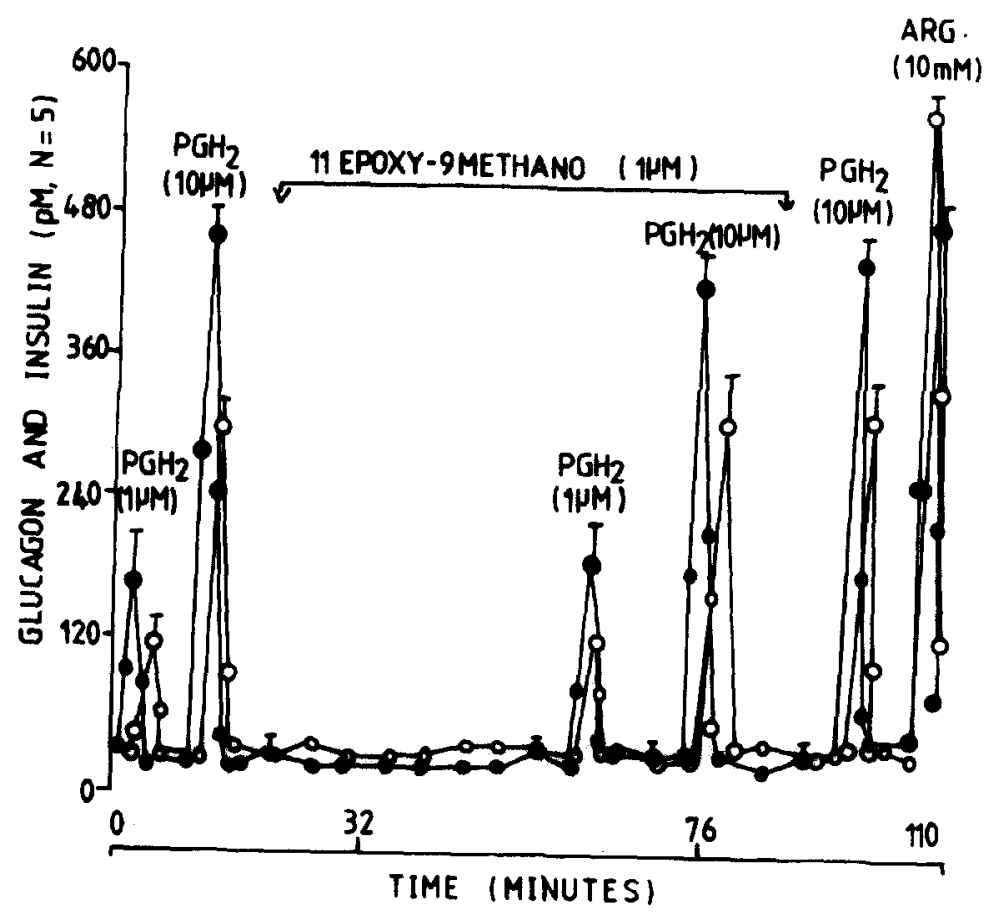

Fig. 2. Glucagon and insulin secretion during perfusion of pancreas with $\mathrm{PGH}_{2}$ and endoperoxide analog. Hormone values are mean \pm SEM for 5 observations.

Figure 2 illustrates levels of glucagon and insulin secretion corresponding to $\mathrm{PGH}_{2}$ injections described above and illustrated in Figure 1. The levels of glucagon (solid circle) and insulin (open circle) secretion induced by $\mathrm{PGH}_{2}$ ( 1 or $10 \mathrm{uM}$ ) before, during and after perfusing the pancreata with endoperoxide analog were not significantly different $(P<0.10)$. The release of glucagon occurred more rapidly than that of insulin but the magnitude of the responses in both hormones were similar. Endoperoxide analog alone did not induce glucagon or insulin secretion (Figure 1 and Table 1). Arginine (10 mM) administered to the pancreas at the end of the perfusion caused a significant increase in the levels of both hormones. This indicates that the isolated perfused pancreas was still capable of normal secretory response to a common secretagogue.

In Table 1 are shown values of glucagon and insulin secreted in response to either $\mathrm{PGH}_{2}$, the endoperoxide analog or $\mathrm{PGE}_{2}$; and the corresponding quantitative changes in perfusion pressure. 11-epoxy-9-methano analog of $\mathrm{PGH}_{2}$ (1 uMl) alone caused significant 


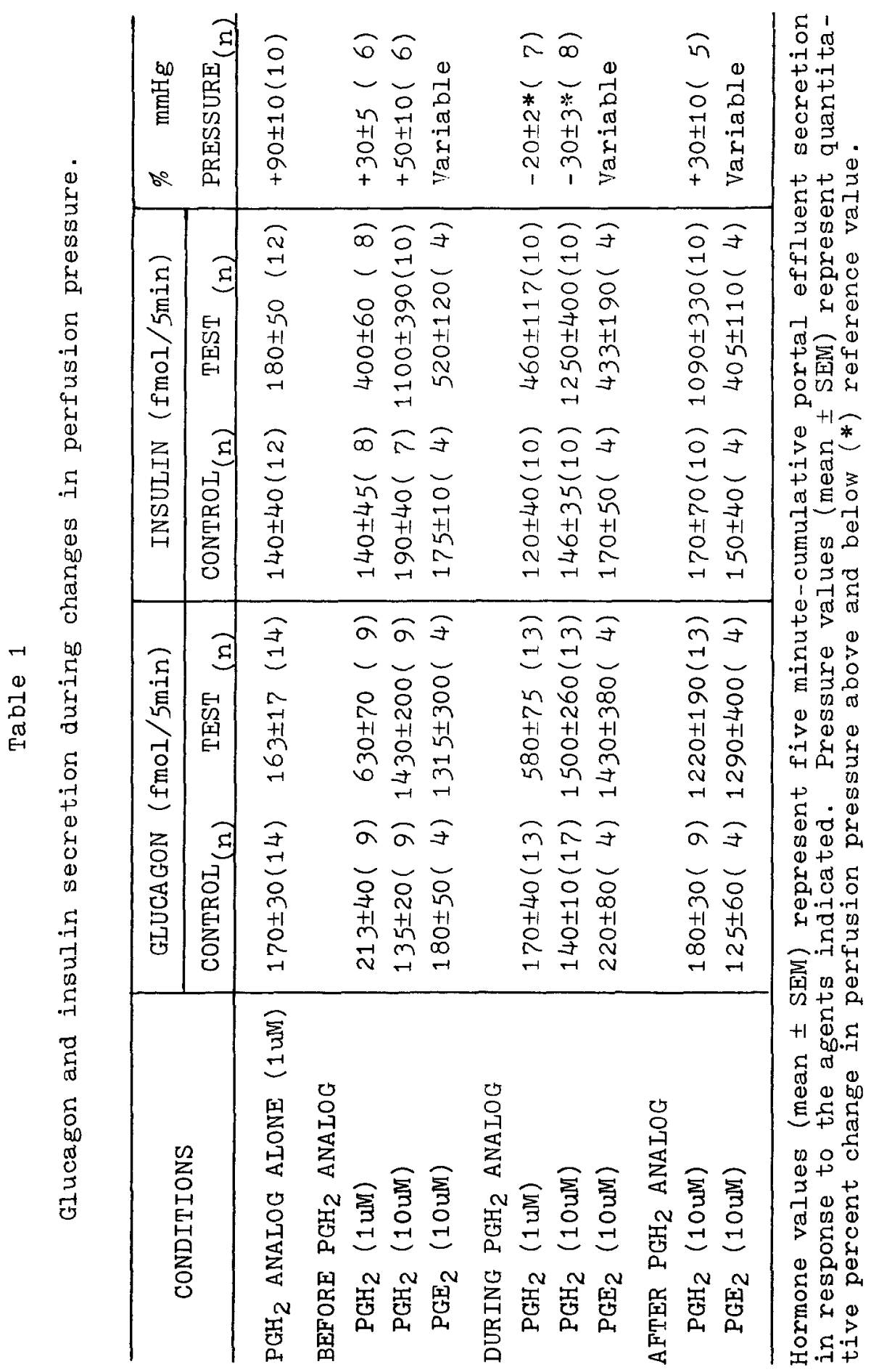


and persistent elevation in pressure $(90 \%$ increase above baseline, last column) without significant effect on hormone release (170 \pm 30 vs $163 \pm 17$, glucagon and $140 \pm 40$ vs $180 \pm 50$, insulin). Increases in glucagon and insulin levels occurred consistently in response to $\mathrm{PGH}_{2}$ and $\mathrm{PGE}_{2}$ (10 uly) before, during and after perfusing the pancreata with the analog. Although hormone secretion was not significantly altered by the analog during concurrent perfusion of the analog with two concentrations of $\mathrm{PGH}_{2}$ ( 1 and $10 \mathrm{uMI}$ ), the perfusion pressure decreased significantly $20 \pm 2 \%$ and $30 \pm 3 \%$ respectively) below the observed pressure increase caused by the analog alone. Changes in pressure due to $\mathrm{PGE}_{2}$ (10 uM) were inconsistent and variable. The levels of hormone release and changes in preasure ( $\mathrm{PGH}_{2}$ only) induced by either $\mathrm{PGH}_{2}$ or $\mathrm{PGE}_{2}$ after 60 minutes exposure of pancreas to the analog, were comparable to those obtained prior to perfusion with the analog (Table 1).

\section{DISCUSSION}

This investigation was carried out to determine the relationship between prostaglandin-induced changes in vascular resistance and endocrine pancreas secretion in the perfused pancreas. The results demonstrate that there is no direct association between perfusion pressure in the pancreas and portal venous glucagon and insulin secretion (Figures 1 and 2). Although $\mathrm{PGH}_{2}$ decreased high perfusion pressure caused by 11-epoxy-9-methano analog of $\mathrm{PGH}_{2}$, hormone secretion induced by $\mathrm{PGH}_{2}$ was not significantly affected (Figures 1 and 2 ). Since the perfusion flow rate was maintained constant at $2.5 \mathrm{~mL}$ per minute, the observed changes in perfusion pressure shown in Figure 1 and in Table 1 are interpreted as alterations in vascular resistance.

The data presented in these studies dissociate local pressor and depressor action of prostaglandins from modulation of hormone release, and are in agreement with those of Saunders and Moser (7) who reported that the amount of insulin release by perfused pancreas was unaffected by $P G F 2 \alpha$-induced vasoconstriction. Mandelbaum and Morgan (13) manipulated canine extracorporeal circulation both mechanically and by use of vasoactive agents in vivo and reported no change in rate of insulin secretion despite elevated pancreatic blood flow. Growth hormone infusion and mechanical constriction of the inferior pancreatic artery diminished blood flow without proportionate decrease in insulin output in partially depancreatized dogs (14). However, largely because kallikrein, bradykinin and histamine increase capillary circulation, stimulate the basal- and the glucagon-induced insuIin secretion in the dog (15), a direct relationship between secretion and alteration in microvasotone of endocrine pancreas has been suggested $(15,16)$. Data shown in Table 1 are in disagreement not only with the concept of direct correlation between changes in vascular tone and insulin release, but provide further evidence (for the first time to the authors' knowledge) to dissociate prostaglandin-induced glucagon secretion from alteration in vascular resistance. We had reported previously that the 
perfusion of isolated rat pancreas over 1 to $10 \mathrm{~min}$ period with $\mathrm{PGE}_{1}, \mathrm{PGE}_{2}$ or $\mathrm{PGF} 2 \alpha$ augmented the release of glucagon and insulin (11), and also that $\mathrm{PGH}_{2}$ is a potent secretagogue for both pancreatic hormones (10).

The mechanism of pressor and secretagogue effects of prostaglandins appears to be specific and separate. The attenuation of the endoperoxide analog-induced high perfusion pressure by $\mathrm{PGH}_{2}$ (Figure 1 and Table 1) could indicate an action on the same receptor by $\mathrm{PGH}_{2}$ and the analog as previously reported $(1,4,5)$. $\mathrm{PGH}_{2}$ could have a higher affinity for the receptor but lower pressor activity than the analog. Therefore, concurrent administration of the two results in displacement of the analog by $\mathrm{PGH}_{2}$. However, since the perfusion of pancreas with the analog did not enhance hormone release, it is possible that separate prostaglandin receptors exist for regulation of vasotone and modulation of secretion in endocrine pancreas. The secretagogue effect of $\mathrm{PGH}_{2}$ could also be due to further conversion to other prostanoids. Robertson (17) has reported inhibition by intravenous infusion of $\mathrm{PGE}_{1}$ of insulin release independent of alterations in vascular resistance or stimulation of the alpha-adrenergic receptors.

The mechanism by which prostaglandins modulate the secretory activity of endocrine glands is often attributed to interaction of their specific receptors with adenylate cyclase (18), since prostaglandins generally elevate levels of the nucleotide in tissues and affect metabolic functions regulated by cyclic AMP. The stimulant effect of prostaglandins endoperoxide on endocrine pancreas secretion could involve alteration in intracellular calcium concentrations although Hertelendy et al. (19) have reported that the prostaglandins are not acting as ionophores. Mishima and Kuriyama (20) reported depolarization of guinea pig stomach longitudinal muscle membrane by $\mathrm{PGE}_{1}, \mathrm{PGE}_{2}$ or $\mathrm{PGF}_{2} \alpha$ suggesting that these prostaglandins may increase calcium influx by stimulating electrical activity of the membrane. Change in membrane depolarization with the associated calcium influx in response to pancreatic endocrine hormone secretagogues is a wellestablished phenomenon.

We have provided evidence that the epoxymethano analog of $\mathrm{PGH}_{2}$ exerts rapid and potent effect on vascular tone in perfused pancreas without significant effect on hormone release in response to $\mathrm{PGH}_{2}$ and $\mathrm{PGE}_{2}$. It is concluded that nonpathologic changes in microvasotone in the pancreas do not significantly alter secretory activity of the endocrine pancreas.

\section{ACKNOWLEDGEMENTS}

These studies were supported in part by United States Public Health Service grants AM-21192, AM-02244 and AM-20572. The radioimmunoassays for glucagon and insulin were performed in the Irigand Assay Core Laboratory of the Michigan Diabetes Research and Training Center. 


\section{REFERENCES}

1. Bundy GL. The synthesis of prostaglandin endoperoxide analogs: Tetrahedron Lett. 24:1957-1960, 1975.

2. Corey EJ, Nicolaou KC, Machida Y, Malmsten CL, Samuelsson B. Synthesis and biological properties of a 9,11-azoprostanoid: Highly active biochemical mimic of prostaglandin endoperoxides. Proc. Natl. Acad. Sci. USA 72:3353$3358,1975$.

3. Bennett A, Posner J. Studies on prostaglandin antagonists. $\mathrm{Br}$. J. Pharmac. 42:584-594, 1971 .

4. Gorman RR, Bundy GL, Peterson DC, Sun FF, Miller OV, Fitzpatrick FA. Inhibition of human platelet thromboxane synthetase by 9,11-azoprosta-5,13-dienoic acid. Proc. Natl. Acad. Sci. USA 74(9): 4007-4011, 1977.

5. Gorman RR, Fitzpatrick FA, Miller OV. A selective thromboxane synthetase inhibitor blocks the cAMP lowering activity of $\mathrm{PGH}_{2}$. B.B.R.C. 79:305-313, 1977 .

6. Chapnick BM, Feigen LP, Flemming JM, Hyman AL, Kadowtz PJ. Comparison of the effects of prostaglandin $\mathrm{H}_{2}$ and an analog of prostaglandin $\mathrm{H}_{2}$ on the intestinal vascular bed of the dog. The Pharmacologist 19:148, 1977.

7. Saunders RN, Moser CA. Changes in vascular resistance induced by prostaglandin $\mathrm{E}_{2}$ and $\mathrm{F}_{2 \alpha}$ in the isolated rat pancreas. Arch. Int. Pharmacodyn. 197:86-92, 1972.

8. Kaley G, Weiner R. Prostaglandin E: A potential mediator of the inflammatory response. Ann. N.Y. Acad. Sci. 180:338, 1971 .

9. Pek S, Tai T-Y, Elster A, Fajans SS. Augmentation by prostaglandins of glucagon (IRG) and insulin (IRI) release from isolated rat pancreas. Clin. Res. 22:619, 1974.

10. Akpan JO, Hurley MC, Pek S, Lands WEM. The effect of prostaglandins on secretion of glucagon and insulin by the perfused rat pancreas. Can. J. Biochem. 57:540-547, 1979.

11. Pek S, Tai T-Y, Elster A. Stimulatory effects of prostaglandins $\mathrm{E}-1, \mathrm{E}-2$, and $\mathrm{F}-2$ alpha on glucagon and insulin release in vitro. Diabetes 27:801-809, 1978 .

12. Pek S. Glucagon and insulin. pp 122-140 in Nuclear Medicine: Endocrinology. (B Rothfield ed) B. Lippincott, Philadelphia, 1978. 
13. Mandelbaum I, Morgan CR. Pancreatic blood flow and its relationship to insulin secretion during extracorporeal circulation. Annals of Surgery 170(5):753-758, 1969.

14. Rappaport AM, Kawamura T, Davidson JK, Lin BJ, Ohira S, Zeigler M, Coddling JA, Henderson J, Haist RE., Effects of hormones and of blood flow on insulin output of isolated pancreas in situ. Am. J. Physiol. 22:343-348, 1971.

15. Vance JE, Bragg $\mathrm{SC}$. Insulin release in response to microvasoactive substances. Diabetes 18:326-327, 1969.

16. Mintz DH, Finster J, Stept M. Effect of angiotension II on immunoreactive insulin. J. Clin. Endocrinol. 27:671-678, 1967.

17. Robertson RP. In vivo insulin secretion: Prostaglandins and adrenergic interrelationships. Prostaglandins 6:501$508,1974$.

18. Johnson DG, Thompson WJ, Williams RH. Regulation of adenylyl cyclase from isolated pancreatic islets by prostaglandins and guanosine 5-triphosphate. Biochemistry 13:1920-1924, 1974 .

19. Hertelendy F, Todd H, Narconis RJ Jr. Studies on growth hormone secretion IX prostaglandins do not act like ionophores. Prostaglandins 15:575-590, 1978.

20. Mishima $K$, Kuriyama $H$. Effect of prostaglandins on electrical and mechanical activities of the guinea pig stomach. Jpn. J. Physiol. 26:537-548, 1976. 